\title{
Influence of Solution Heat Treatment on the Microstructure, Hardness and Stress Corrosion Behavior of Extruded Resoloy ${ }^{\circledR}$
}

\author{
P. MAIER (i) ${ }^{1,3}$ A. STEINACKER,${ }^{2}$ B. CLAUSIUS,${ }^{1}$ and N. $\mathrm{HORT}^{2}$ \\ 1.-University of Applied Sciences Stralsund, Stralsund, Germany. 2.-Helmholtz-Zentrum \\ Geesthacht, Magnesium Innovation Centre, Geesthacht, Germany. 3.-e-mail: \\ petra.maier@hochschule-stralsund.de
}

The microstructural changes and corrosion response of Resoloy ${ }^{\circledR}$, a resorbable Mg-Dy-based alloy, are the focus of this study. Hardness, tensile and compressive, and bending tests are used to monitor the changes in the mechanical properties of this material. The corrosion behavior is investigated by stress corrosion of C-rings. Hot-extruded tubes are solution heat-treated at different temperatures and times. The as-extruded condition shows a homogeneous fine-grained microstructure with matrix long-period stacking-ordered (LPSO) structures. Heat treatment at low temperatures and for short times does not significantly change the microstructure but reduces the hardness. Solution heat treatment at relatively high annealing temperatures and long annealing times causes grain growth, resulting in reduced hardness. The microstructure becomes inhomogeneous, medium-sized grains grow, the matrix LPSO structures dissolve, and small bulk LPSO phases develop. The matrix LPSO structures have a positive effect on the corrosion behavior. In particular, the short-term annealing condition shows the most uniform corrosion morphology. Resoloy $^{\circledR}$ is not free of pitting corrosion, but none of the samples fails by cracking.

\section{INTRODUCTION}

The interest in bioabsorbable metals as implants for temporary fixation continues to grow. ${ }^{1-3}$ Magnesium alloys show significant promise, and the WE43 alloy is already used clinically. ${ }^{4,5}$ WE43 is a Mg-Y-RE-based alloy, where RE represents a mixture of rare earth elements containing primarily $\mathrm{Nd}$. WE43 is a high-strength alloy with an acceptable biological response. ${ }^{6-8}$ The alloying, manufacturing route and post-heat treatment influence the mechanical and corrosion properties of this material. $\mathrm{Nd}$, for example, is known to form stable intermetallic phases at grain boundaries, as $\mathrm{Nd}$ has a low solid solubility in $\mathrm{Mg}$ and is therefore added to provide precipitation strengthening. It has also been reported that $\mathrm{Nd}$ is added to improve the corrosion resistance of $\mathrm{Mg}$ alloys by reducing the effect of galvanic corrosion between the secondary phases and the matrix and making the surface film more passive. ${ }^{9-11}$
Whereas WE43 was originally developed as a creep-resistant alloy for aerospace applications, the alloy in this study was developed specifically for absorbable implants by MEKO Laser Materials Processing, Germany, and the Helmholtz Center Geesthacht, Germany. ${ }^{12}$ Resoloy ${ }^{\circledR}$ is an alloy based on Mg10Dy-1Nd with excellent strength and ductility. Dy has a high solubility in $\mathrm{Mg}$ (23.5 wt.\% at $561^{\circ} \mathrm{C}$ ), which enables tuning of both the mechanical and corrosion properties through the Dy content and heat treatment. Dy has also shown good cytocompatibility according to an in vitro study on its cytotoxicity and inflammatory response. ${ }^{13}$ In the as-cast condition, Mg-10Dy alloy exhibits the best combination of mechanical and corrosion properties, ${ }^{14}$ and alloying $\mathrm{Gd}$ and $\mathrm{Zr}$ has yielded an improvement in the mechanical properties. ${ }^{15}$ Considerable age hardening is recognized in alloys with higher Dy contents. However, in comparison to $\mathrm{Mg}-$ Gd (Gd has a similar high solubility, and Mg-10Gd is also used as a base alloy), Mg-Dy alloys are less stable at elevated temperatures. ${ }^{16}$ In a study by $\mathrm{Li}$ 
et al., ${ }^{17}$ a rapid aging response was found in a $\mathrm{Mg}$ Dy-Gd-Nd alloy. In-situ solidification experiments on Mg20Dy and Mg20Dy alloyed with $\mathrm{Zr}^{18}$ revealed $\mathrm{Mg}_{24} \mathrm{Dy}_{5}$ as a secondary phase.

$\mathrm{Zn}$ is a very common alloying element that forms intermetallic phases with $\mathrm{Zr}, \mathrm{RE}$ and $\mathrm{Mg}$ and reduces the grain size. Both of these effects result in improved mechanical properties and enhanced corrosion resistance. ${ }^{19}$ Zirconium is added to $\mathrm{Mg}$ alloys as a grain refiner by providing nucleating sites or by restricting grain growth. According to Hall-Petch strengthening, grain refinement improves the yield strength. The solubility of $\mathrm{Zr}$ at room temperature is $0.2 \mathrm{wt} . \%$. $\mathrm{Zr}$ is found to be biocompatible in small amounts. Yang ${ }^{20}$ has shown that the addition of $0.2 \mathrm{wt} . \% \mathrm{Zr}$ to a binary $\mathrm{Mg}$-Dy alloy increases the tensile yield strength of the alloy by approximately $20-50 \%$ and the elongation from $5 \%$ to $\sim 22 \%$ (also an important effect of grain refinement). Considering their strength and good biocompatibility, Mg-Zn-Zr alloys (ZK alloys) are considered biodegradable magnesium alloys. ${ }^{21} \mathrm{ZK}$ alloys with smaller amounts of zinc and zirconium, ZK30, show lower degradation rates and less hydrogen evolution than ZK60, with higher zinc and zirconium contents. ${ }^{22}$ ZK30 alloy showed insignificant cytotoxicity against bone marrow stromal cells compared with biocompatible hydroxyapatite (HA) and a WE-type alloy.

With $\mathrm{Zn}$ and RE siting on close-packed atomic layers, some Mg-RE-Zn systems $(\mathrm{RE}=\mathrm{Y}, \mathrm{Gd}, \mathrm{Tb}$, Dy, Ho, Er, Tm) form various novel long-period stacking-ordered (LPSO) structures ${ }^{23-25}$ which appear in bulk, lamellar block and rod shapes and increase plasticity and toughness by significant amounts. ${ }^{26-28}$ Furthermore, due to their barrier effects, LPSO structures impact the corrosion resistance of magnesium alloys. Evenly distributed lamellar LPSO structures throughout the whole grain provide better corrosion resistance than the coarser accumulations often observed at grain boundaries. ${ }^{29}$ In a study by Leng et al., ${ }^{30}$ the mechanical properties of Mg-Y-Er-Zn alloy with LPSO structures could be maintained at a high level under immersion in simulated body fluid (SBF) for $240 \mathrm{~h}$. It has been reported that RE improved the formation of passive layers and slowed the corrosion of the matrix. ${ }^{31,32}$

In a study by Steinacker et al., ${ }^{33}$ heat treatment of Resoloy ${ }^{\circledR}$ (extruded EZK1110 alloy) yielded an increased number of LPSO structures with increasing heat treatment time. These LPSO structures form either within the matrix or as bulk phases by diffusion of alloying elements out of the intermetallic phase. Their individual chemical composition is influenced by the temperature and time of the heat treatment. With optimized heat treatment, a uniform distribution of LPSO phases and thus improved corrosion behavior can be achieved. An optimized grain size, a fine distribution of intermetallics and the right amount of LPSO phase, which acts as a barrier to the corrosion process, have a positive effect on corrosion behavior. In the study by Steinacker et al., ${ }^{33}$ solution heat-treated Resoloy ${ }^{\circledR}$ with optimized LPSO structures reaches low corrosion rates similar to those of the finerecrystallized as-extruded condition. However, the study only covers corrosion rates for up to 7 days. Future work should extend the corrosion test duration and ensure that the manufacturing route has been optimized to meet the required mechanical and corrosion properties.

Biomedical applications require a moderate, homogeneous corrosion rate to avoid strong hydrogen evolution and pitting corrosion. The corrosion morphology is often characterized by the appearance of local corrosion. The amount of pitting corrosion can be seen either by visual observation or by calculation of the area percentage of the corroded surface. According to ASTM guidance, pitting can be described by the shape, size, and number of pits. ${ }^{34}$ Harmful pits are deep and narrow, causing a strong reduction in the cross-sectional area and increased stress intensity during mechanical loading, and acting as notches and therefore as crack initiators. Harmless pits are wide and shallow; if these pits overlap during corrosion, a uniform corrosion morphology develops. Furthermore, the pitting factor resulting from the deepest corrosion pits in relation to the average corrosion, as well as the shape and size of the corrosion pits, is used to describe the corrosion morphology. ${ }^{35}$ The corrosion behavior depends on various factors, such as the grain size, size and distribution of intermetallics, thermomechanical history, and surface quality.

However, the corrosion rate of Resoloy ${ }^{\circledR}$ is relatively low. ${ }^{12}$ The alloying elements and their combination cause a complex microstructure, which has an important influence on the corrosion behavior. Resoloy $^{\circledR}$ in wire form, produced by Fort Wayne Metals, ${ }^{36}$ provides tensile strengths exceeding $500 \mathrm{MPa}$ in the cold drawn state. Additional annealing reduces the strength but substantially increases the ductility. The high elasticity of Resoloy ${ }^{\circledR}$ provides excellent fatigue life in air. ${ }^{37} \mathrm{~A}$ study still in progress $^{38}$ presents the superior in vivo handling properties of Resoloy ${ }^{\circledR}$ as filaments for peripheral nerve repair compared to pure $\mathrm{Mg}$ monofilaments; Resoloy ${ }^{\circledR}$ filaments are more flexible and resistant to damage than pure $\mathrm{Mg}$ monofilaments. Furthermore, the Dy-containing precipitates do not appear to be toxic.

Magnesium alloys are susceptible to stress corrosion cracking, but certain alloying elements increase the stress corrosion cracking (SCC) resistance. ${ }^{41,42}$ After hot deformation, $\mathrm{Mg}-\mathrm{Y}-\mathrm{Zn}^{43}$ shows good resistance to SCC, and Rokhlin ${ }^{44}$ reported that $\mathrm{Nd}$ addition to $\mathrm{Mg}-\mathrm{Zn}-\mathrm{Zr}$ increased SCC resistance. There are no data found in the literature on the stress corrosion of Resoloy ${ }^{\circledR}$. Even long-term U-bend or C-ring tests offer advantages in terms of ease of fabrication and methodology, ${ }^{39,40}$ but are hardly 
applied to magnesium, mostly due to the high corrosion rate of magnesium alloys, which reduces the sample volume rather than causing stress corrosion. Typically, the pitting corrosion (leading to increased stress intensity because of the notch effect) in, and strong volume loss of, the samples are expected to cause failure by mechanical overload instead of stress corrosion cracking. However, since the corrosion rate of Resoloy ${ }^{\circledR}$ is rather low, C-ring tests with constant strain have been chosen to investigate material extruded in tubes.

\section{EXPERIMENTAL}

\section{Processing and Materials Testing}

Resoloy ${ }^{\circledR}(\mathrm{Mg}-10 \mathrm{Dy}-1 \mathrm{Nd}-1 \mathrm{Zn}-0.2 \mathrm{Zr}$, where chemical composition is given in weight percent) alloy was cast using permanent mold direct chill casting $^{45}$ at the Helmholtz Centre in Geesthacht, Germany. After a short annealing $\left(15 \mathrm{~min}\right.$ at $\left.500^{\circ} \mathrm{C}\right)$, tubes were indirect hot-extruded at the Extrusion Research and Development Center of TU Berlin at an overall temperature of $400^{\circ} \mathrm{C}$, a ram speed of $1.5 \mathrm{~mm} / \mathrm{s}$ and an extrusion ratio of $19: 1$. The asextruded tubes had an outer diameter of $35 \mathrm{~mm}$ with a wall thickness of $5 \mathrm{~mm}$. Annealing and solution heat treatment were performed at two temperatures: $200^{\circ} \mathrm{C}$ for $4 \mathrm{~h}$ and $500^{\circ} \mathrm{C}$ for 24,48 and $72 \mathrm{~h}$. The samples were cooled in water of a temperature of $55^{\circ} \mathrm{C}$. To understand the influence of $\mathrm{Zr}$ and $\mathrm{Zn}, \mathrm{Mg}-10 \mathrm{Dy}$ and $\mathrm{Mg}-10 \mathrm{Dy}-1 \mathrm{Nd}$ tubes were used for comparison of the mechanical properties.

The rings of the tubes for metallographic and hardness investigations were prepared for optical microscopy by grinding with $\mathrm{SiC}$ paper to a grit size of 4000 . Afterwards, the samples were polished with water-free colloidal silica and 3, 1 and $0.04 \mu \mathrm{m}$ diamond paste. The samples were then cleaned with ethanol and dried with hot air. The samples were etched in a solution prepared with $4.2 \mathrm{~g}$ picric acid, $10 \mathrm{ml}$ acetic acid 100\%, $10 \mathrm{ml}$ distilled water, and $70 \mathrm{ml}$ ethanol. The samples were examined with light microscopy (Leica DMi 8 A). IMAGIC IMS software was used for the evaluation of the micrographs, including grain size measurements using the line intercept technique.

For analysis with scanning electron microscopy (SEM), the specimens were prepared with the method for optical microscopy without etching. A TESCAN Vega3 was used for imaging, and the attached energy dispersive X-ray spectroscopy (EDS) system was used to analyze the chemical composition. For transmission electron microscopy (TEM), the specimens were first manually ground to approximately $150 \mu \mathrm{m}$ thickness. Discs $3 \mathrm{~mm}$ in diameter were cut from the prepared foil. The discs were further thinned by electropolishing using a Fishione twin jet polisher with $1.5 \%$ perchloric acid at a voltage of $50 \mathrm{~V}$ and a temperature of $-45^{\circ} \mathrm{C}$. The TEM examination was conducted with an FEI
CM200 transmission electron microscope with an attached EDS system.

The Vickers hardnesses, HV1 and HV0.2, were tested with a ZHU2.5 by Zwick with 30 indents per condition, and the average values are reported. The tensile properties were measured at room temperature with a TIRA mechanical testing machine at an initial speed of $2.4 \mathrm{~mm} / \mathrm{min}$. The samples had a gauge length of $20 \mathrm{~mm}$ and were $2 \mathrm{~mm}$ thick and $5 \mathrm{~mm}$ wide. Compression tests were performed on cylindrical samples with a height of $4 \mathrm{~mm}$ and a diameter of $2 \mathrm{~mm}$.

\section{C-ring tests}

Figure 1a shows the geometry of the C-ring samples. The samples were machined from extruded tubes with an outer diameter of $34 \mathrm{~mm}$. The wall thickness was chosen to be $2 \mathrm{~mm}$. Bending tests (Fig. 1b) were performed with a TIRA testing machine to evaluate the elastic-plastic transition, the plastic strengthening, and the amount of stored elastic energy. The force-displacement curves were monitored up to a displacement of $7 \mathrm{~mm}$, at which point the geometry of the C-Ring changed into a "closed" elliptic geometry. Because the test had neither a uniaxial loading condition nor a standard 3 -point bending test geometry, there was no calculation of stress-strain. The force-displacement curves were only used for comparison with those from the identical C-ring geometry.

\section{Corrosion Tests}

Two types of loading conditions were applied in the immersion tests. (1) Plastically deformed samples (after spring-back) were corroded to investigate the influence of work (strain) hardening, and (2) elastic-plastic-loaded samples were corroded to determine the influence of additional elastic loading (stress corrosion) on the corrosion behavior. Here, a POM setup was used to clamp the C-rings to a certain strain (displacement), as shown in Fig. 1c. The POM setup consisted of plates and screws and was designed to eliminate creep. In (1), the samples were bent to $7 \mathrm{~mm}$ displacement, moved from the testing machine to allow spring back and then corroded over 7 and 20 days in $330 \mathrm{ml}$ stagnant Ringer solution ( 3 samples each) at $37^{\circ} \mathrm{C}$ in a glass beaker with a cover. Before corrosion, the samples were cleaned in an ultrasonic bath in ethanol. Ringer solution, being more aggressive than HBSS or DMEM, was chosen for the corrosion tests. The $\mathrm{pH}$ value did not exceed 8.5. In (2), the C-ring samples were elastically and plastically loaded in the POM setup at $7 \mathrm{~mm}$ displacement and held for 20 days in $500 \mathrm{ml}$ Ringer solution (3 samples each) at $37^{\circ} \mathrm{C}$. Figure $1 \mathrm{c}$ shows the C-ring sample during stress corrosion clamped in the POM plates of the setup. To cover the samples in the POM setup with electrolyte, distilled water was added every 5 days to account for evaporative loss. The $\mathrm{pH}$ value did not 
(a)

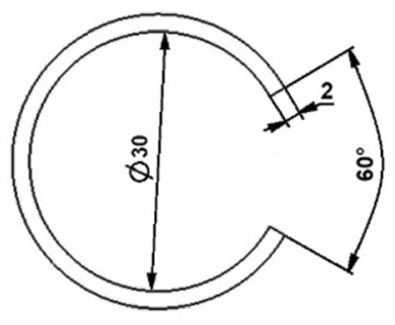

(b)

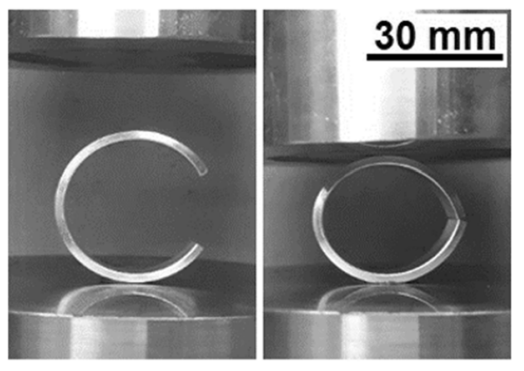

(c)

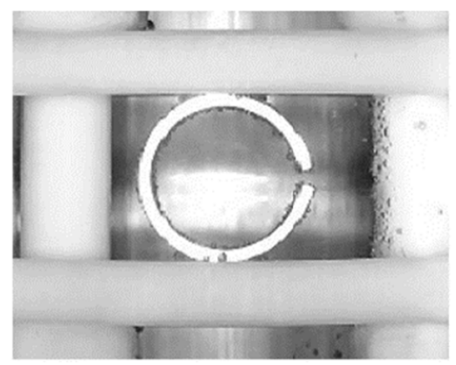

Fig. 1. C-Ring samples: (a) sketch of geometry, (b) bending test, before and after, and (c) during stress corrosion in the POM setup

exceed 8.5 (measured at the end of the immersion test).

\section{Corrosion Morphology}

The corroded C-rings, having a length of $10 \mathrm{~mm}$, were "sectioned" transversely by grinding first to approximately $7 \mathrm{~mm}$ length and then to $5.0 \mathrm{~mm}$ from one of the ring sides. For both steps, the corrosion morphology is determined from the micrographs and described according to ASTM G46-76, ${ }^{34}$ a standard visual chart for rating pitting corrosion. The depth and width of the corrosion pits were used to describe the amount of corrosion.

\section{RESULTS AND DISCUSSION}

\section{Microstructure}

The as-extruded Resoloy ${ }^{\circledR}$ shows a homogeneous, small-grained recrystallized microstructure; see transverse micrographs in Fig. 2a and b. The average grain size is $9.4 \pm 6.62 \mu \mathrm{m}$. In the longitudinal micrograph (see supplementary Fig. S1), the extrusion direction can be seen by the alignment of the MgDyNdZn intermetallics, which are mostly of the composition $\mathrm{Mg}_{67} \mathrm{Dy}_{11} \mathrm{Nd}_{5} \mathrm{Zn}_{11}$. Lamellar LPSO structures precipitated during the recrystallization process within the matrix (lamellar matrix LPSO) during hot extrusion. Short annealing at $200^{\circ} \mathrm{C}$ for $4 \mathrm{~h}$ does not significantly change the microstructure, and the average grain size is $8.77 \pm 6.90 \mu \mathrm{m}$ (see Fig. 2c). There is still a significant difference between the transverse cross-section and the longitudinal microstructure regarding the alignment of the second phase in the extrusion direction. Solution heat treatment at $500^{\circ} \mathrm{C}$ results in grain growth (see Fig. 3d-f). After $24 \mathrm{~h}$, the grains have grown to $33.1 \pm 28.25 \mu \mathrm{m}$, and, after $48 \mathrm{~h}$, to $45.63 \pm 41.23 \mu \mathrm{m}$. There is still a difference between the microstructures in the transverse and longitudinal directions, but this difference is not as pronounced. During solution heat treatment, the composition of the MgDyNdZn phases changes due to diffusion of Dy, Nd and $\mathrm{Zn}$ out of this phase. Bulk LPSO phases develop at grain boundaries and boundary triple points but also within the grains as individual new grains in rod or block shapes. The lamellar matrix LPSO becomes less pronounced. With increasing annealing time, the bulk LPSO phases become increasingly larger (also because some of them cluster). However, these phases do not prevent the grains from growing in general. After $72 \mathrm{~h}$, the average grain size decreases slightly to $39.28 \pm 28.22 \mu \mathrm{m}$. This change is based on the higher number of small bulk LPSO phases, which reduces the average grain size even though grain growth occurs (average grain size without the small bulk LPSO phases increases constantly up to $72 \mathrm{~h}$ ). There is no difference between the longitudinal microstructure and that of the transverse crosssection.

There seems to be a stronger diffusion of Dy, $\mathrm{Zn}$ and $\mathrm{Nd}$ atoms to the existing lamellar LPSO structures as well as being associated with the formation of new LPSO structures within the matrix: a higher enrichment of $\mathrm{Dy}, \mathrm{Zn}, \mathrm{Nd}$ is found in the matrix containing lamellar LPSO than in the bulk LPSO phases. The composition of the bulk LPSO phase (see marked phase in TEM image in Fig. 3a and $\mathrm{c}$ and EDS spectrum in Fig. 3c) is 23.05 wt.\% Dy, 6.87 wt.\% $\mathrm{Zn}$ and 2.72 wt.\% Nd, whereas the lamellar LPSO structures in the matrix (see marked structure in TEM image and EDS spectrum in Fig. 3b) consist of 31.65 wt.\% Dy, 10.32 wt.\% Zn, 3,51 wt.\% $\mathrm{Nd}$ and 0.07 wt.\% $\mathrm{Zr}$. The matrix areas free of LPSO phases (see TEM image and EDS spectrum in Fig. 3a) show a composition of 10.79 wt.\% Dy, 0.86 wt.\% Zn, 1.32 wt.\% Nd and 0.03 wt.\% $\mathrm{Zr}$.

\section{Mechanical Properties}

Force-displacement curves from the bending tests on the C-rings are shown in Fig. 4a. These curves offer evaluations of the elastic-plastic transition, the bending stiffness (and resulting springback), and the strain-hardening amount (slope in the plastic region). The maximum amount of displacement of $7 \mathrm{~mm}$ was chosen. It can be seen that annealing at $200^{\circ} \mathrm{C}$ for $4 \mathrm{~h}$ does not change the force-displacement curve by a great amount: the bending stiffness, strain hardening and force are similar to those of the as-extruded sample at $7 \mathrm{~mm}$ displacement. This result occurs because there are 
(a)

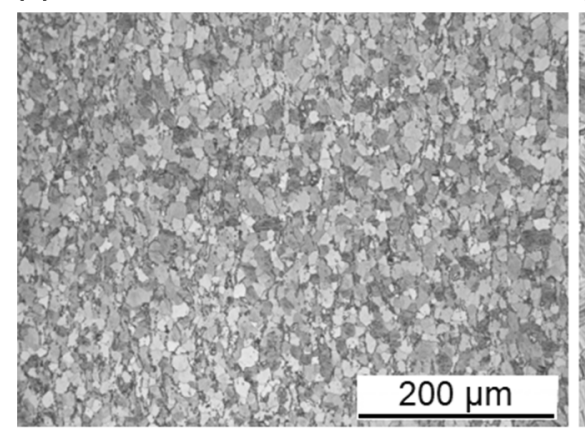

(d)

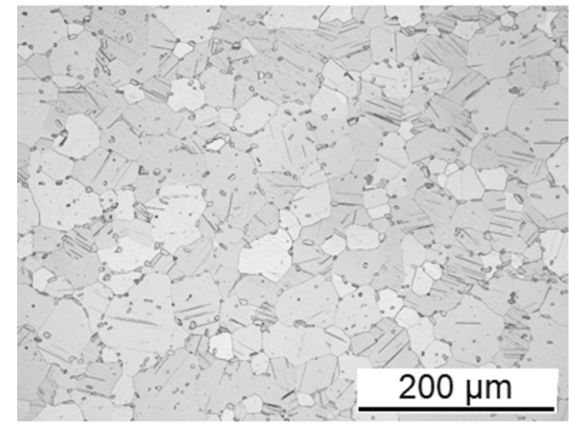

(b)

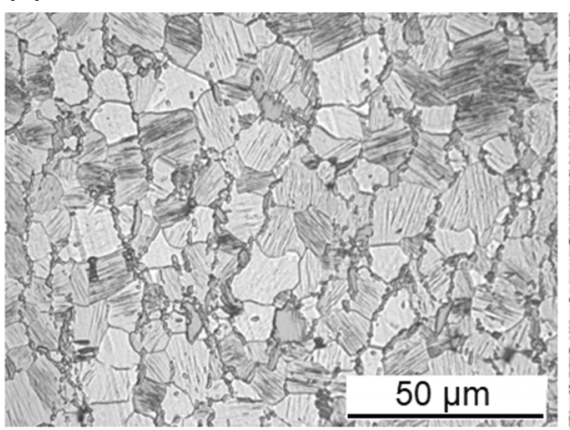

(e)

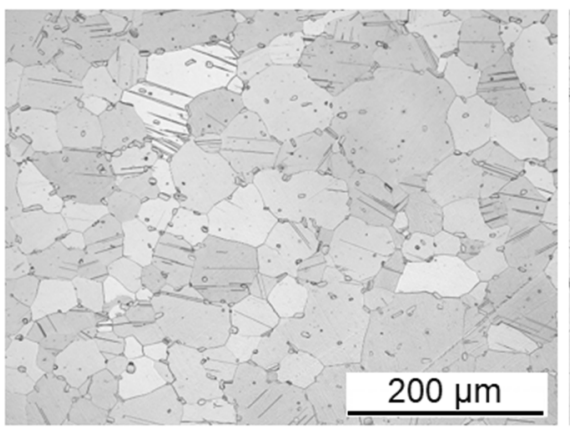

(c)

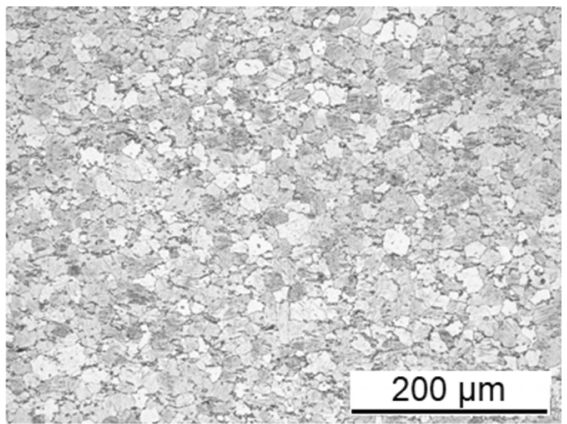

(f)

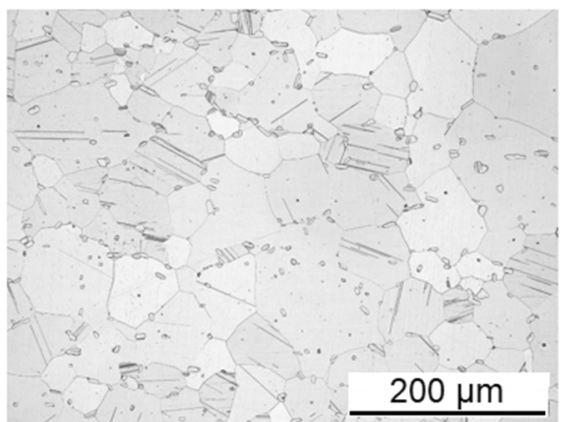

Fig. 2. Transverse microstructures of Resoloy ${ }^{\circledR}$ : (a and b) as-extruded, (c) $200^{\circ} \mathrm{C}$ for $4 \mathrm{~h}$, (d) $500^{\circ} \mathrm{C}$ for $24 \mathrm{~h}$, (e) $500^{\circ} \mathrm{C}$ for $48 \mathrm{~h}$ and (f) $500^{\circ} \mathrm{C}$ for $72 \mathrm{~h}$

(a)
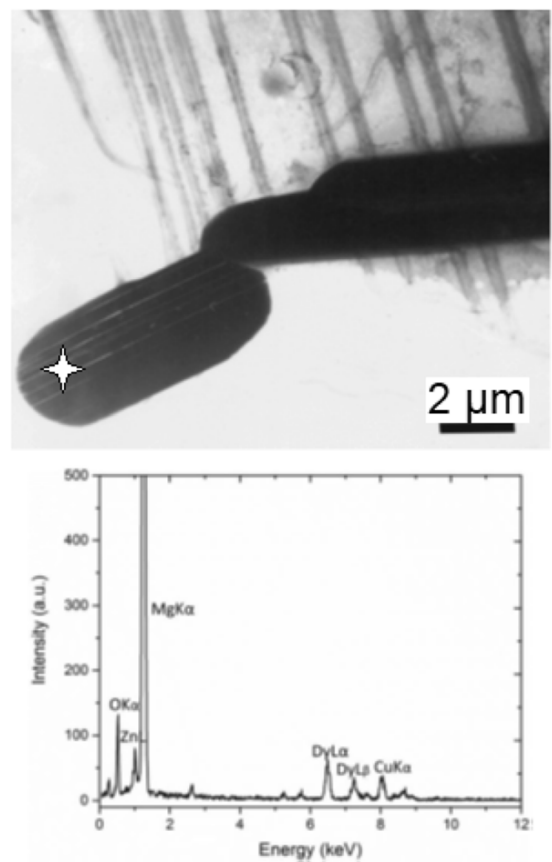

(b)
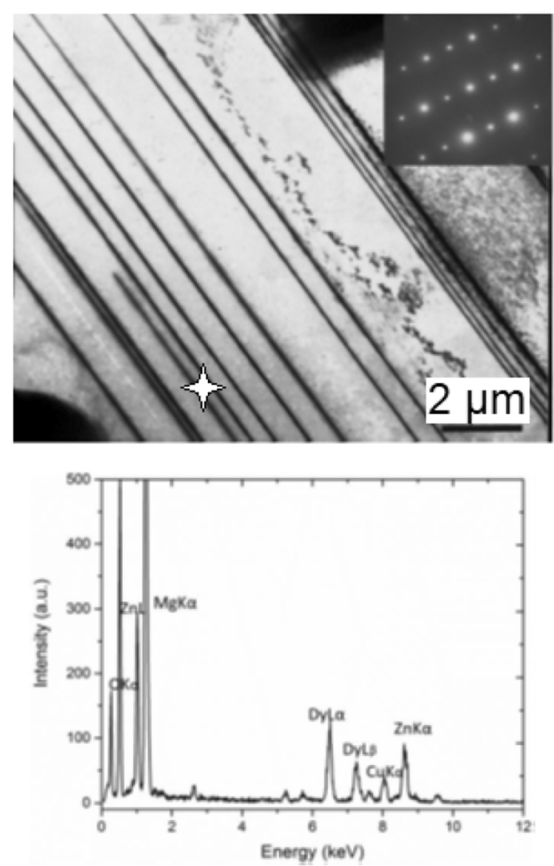

(c)
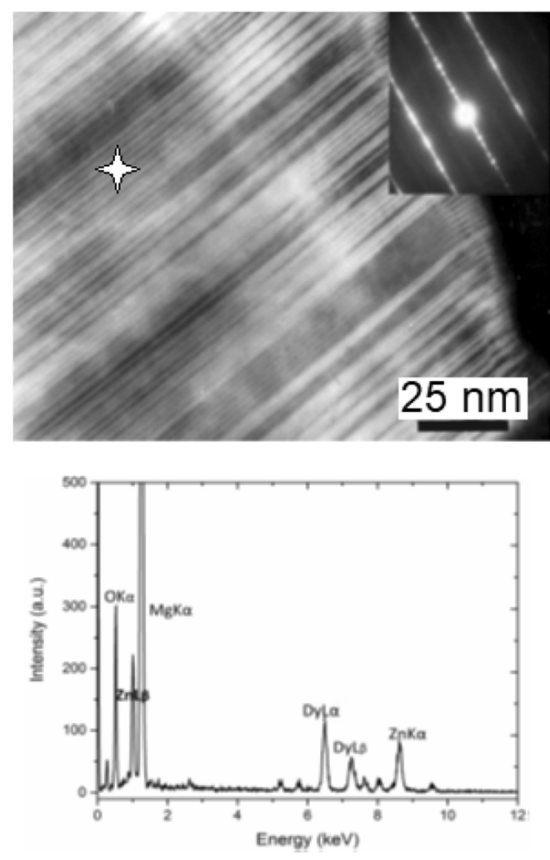

Fig. 3. TEM images of extruded samples heat treated at $500^{\circ} \mathrm{C}$ for $24 \mathrm{~h}$ : (a) matrix and bulk LPSO phase, (b) lamellar LPSO structures within the matrix and (c) higher magnification of bulk LPSO particle and the corresponding EDS spectra (the EDS spectrum in (a) is of the LPSO-free matrix)

no dramatic change in grain size; see the bar chart in Fig. 4b. However, the hardness decreases slightly from $77.7 \mathrm{HV}$ to $73.7 \mathrm{HV}$. Most likely, some residual stress from extrusion is relieved. Solution heat treatment at $500^{\circ} \mathrm{C}$ causes a remarkable change in the force-displacement curves: the 
(a)

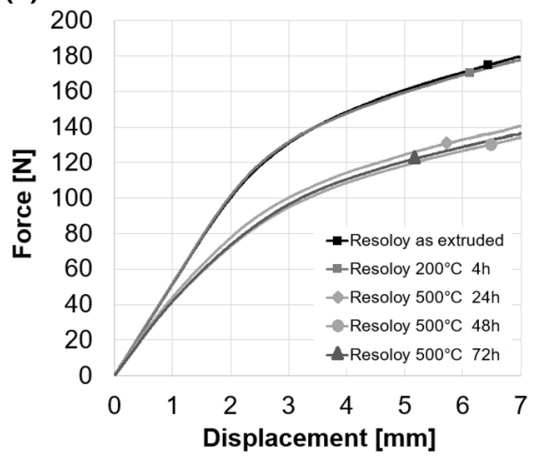

(b)

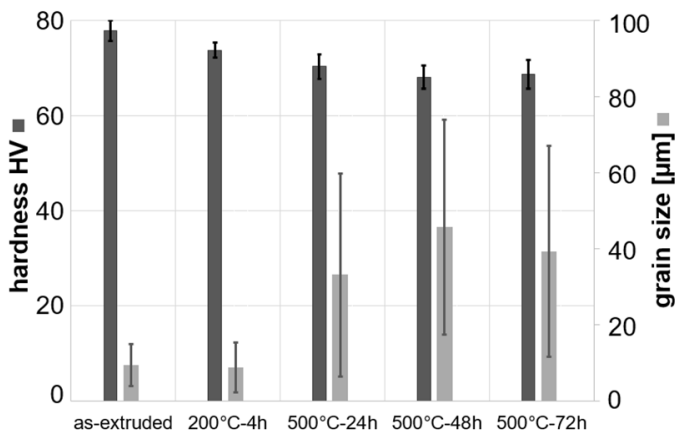

(c)

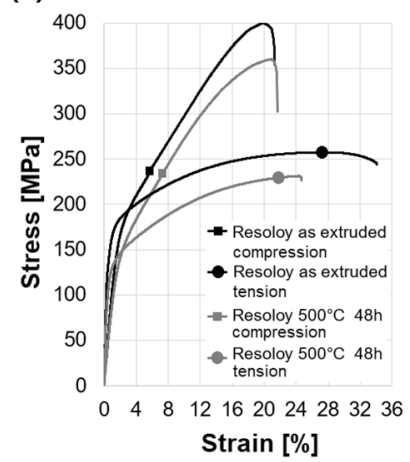

Fig. 4. Mechanical properties of Resoloy ${ }^{\circledR}$ : (a) force-displacement curves of bending tests of up to a displacement of $7 \mathrm{~mm}$, (b) hardness and (c) tensile and compressive properties

bending stiffness is slightly reduced, and yielding starts at lower forces, leading to a smaller force at $7 \mathrm{~mm}$ displacement (from approximately $180 \mathrm{~N}$ to approximately $140 \mathrm{~N}$ ). The increase in grain size from below $10 \mu \mathrm{m}$ to above $30 \mu \mathrm{m}$ is mostly responsible for this result, which agrees with the HallPetch relationship. Again, the hardness offers some detailed characterization: after reduction to $67.9 \mathrm{HV}$ at $48 \mathrm{~h}$, the hardness increases slightly to $68.6 \mathrm{HV}$. Even though coarser grains develop under annealing at $500^{\circ} \mathrm{C}$, the bulk LPSO phases act positively on the hardness and are also responsible for the even smaller average grain size after $72 \mathrm{~h}(39.3 \mu \mathrm{m})$ than after $48 \mathrm{~h}(45.6 \mu \mathrm{m})$. The large standard deviations of the hardness and grain size values of the heat-treated conditions are remarkable. However, the small bulk LPSO phase is smaller than $15 \mu \mathrm{m}$, and the large grains almost reach $150 \mu \mathrm{m}$. Since the elastic-plastic transitions (yield force) and stiffness of the as-extruded samples and samples heat treated at $200^{\circ} \mathrm{C}$ are the highest under bending (Fig. 4a), the amount of spring-back is also higher than that in the heat-treated conditions at $500^{\circ} \mathrm{C}$. Comparing the force data at $7 \mathrm{~mm}$ displacement and the hardness to those of alloys Mg-10Dy and $\mathrm{Mg} 10 \mathrm{Dy}-1 \mathrm{Nd}$ in the as-extruded condition, the following can be found: $130 \mathrm{~N}$ for $\mathrm{Mg}-10 \mathrm{Dy}$ (61.0 $\mathrm{HV}$ ) and $145 \mathrm{~N}$ for Mg10Dy-1Nd (67.1 HV). These results show that adding $\mathrm{Zn}$ and $\mathrm{Zr}$ improves the mechanical properties of the material, mainly based on grain refinement and the formation of lamellar LPSO structures within the matrix.

The stress-strain curves in Fig. 4c show representative curves from the tensile and compression tests of the as-extruded Resoloy ${ }^{\circledR}$ and after heat treatment at $500^{\circ} \mathrm{C}$ for $48 \mathrm{~h}$. In agreement with the bending tests, heat treatment reduces strength; here, for the $500^{\circ} \mathrm{C}-48 \mathrm{~h}$ condition, a reduction in tensile yield strength from (TYS) $130.17 \pm 3.25 \mathrm{MPa}$ to $94.50 \pm 0.71 \mathrm{MPa}$ (ultimate tensile strength from $256.33 \pm 1.53 \mathrm{MPa}$ to $230.00 \pm 1.41 \mathrm{MPa})$ can be found. The elongation at fracture decreases from $30.66 \pm 4.98 \%$ to $24.01 \pm 0.23 \%$. The compression yield strength
(CYS) decreases from $135.50 \pm 6.36 \mathrm{MPa}$ to $102.50 \pm 26.16 \mathrm{MPa}$ (ultimate compression strength from $396.61 \pm 4.30 \mathrm{MPa}$ to $355.68 \pm 6.04 \mathrm{MPa}$ ). Under compressive loading, the strain at compression fracture increases slightly from $17.82 \pm 0.45 \%$ to $18.83 \pm 0.16 \%$. According to the yield strength values, there is no pronounced yield stress asymmetry in the as-extruded Resoloy ${ }^{\circledR}$; CYS/TYS is 1.04. The CYS is slightly higher and increases in relation to the TYS for a heat treatment of $500^{\circ} \mathrm{C}$ for $48 \mathrm{~h}$, with CYS/TYS increasing to 1.08 .

\section{Corrosion}

Figure 5a-e presents photographs of the tension side of the corroded samples after 20 days. There is no thick corrosion layer of white Mg-hydroxide and no significant visual difference between the asextruded Resoloy ${ }^{\circledR}$-only plastically deformed samples corroded over 7 and 20 days and the elasticplastic-loaded samples corroded over 20 days (stress corrosion), the tension and compression sides, or the different heat treatments. All the samples have lost their metallic shine and appear gray to black with some local white corrosion products. However, none of the samples fail during the tests by crack initiation and propagation. From the visual appearance, a general smooth corrosion morphology without large pitting corrosion is expected. The increased amount of corrosion product in Fig. $5 \mathrm{~b}$ and $\mathrm{d}$ indicates localized corrosion, but the proximity to the edge of the sample suggests that residual stress from manufacturing could contribute.

Figure $6 \mathrm{a}-\mathrm{f}$ shows representative cross-sectional macrographs after 20 days of corrosion to evaluate the general morphology (there is no visual corrosion attack in the macrographs after 7 days of corrosion). Comparing Fig. $6 \mathrm{a}$ and $\mathrm{b}$ shows that there is no difference between the only plastically deformed CRing and the elastic-plastic-loaded C-ring. Both Crings show corrosion attack on the tensile side and hardly any attack on the compression side. The pits in the as-extruded condition are mostly elliptical shaped and wide and shallow. Heat treatment at 
(a)

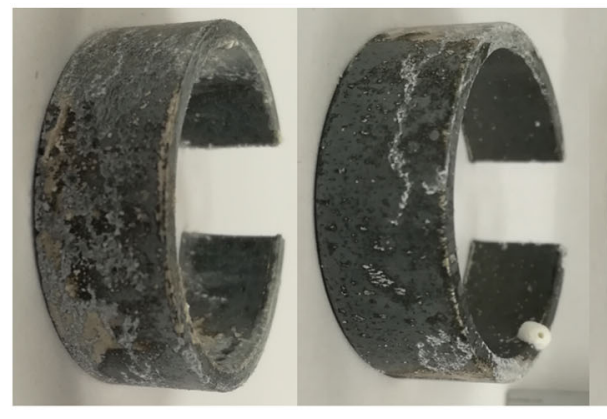

(c)

(d)

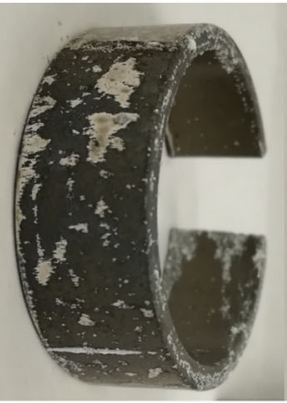

(e)

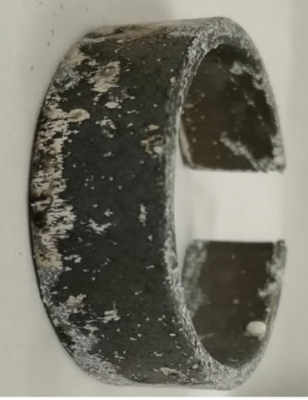

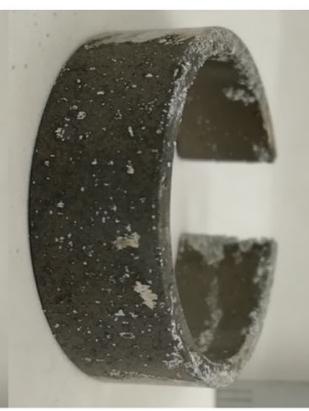

$10 \mathrm{~mm}$

Fig. 5. Corroded C-rings after 20 days: (a) as-extruded, (b) $200^{\circ} \mathrm{C}$ for $4 \mathrm{~h}$, (c) $500^{\circ} \mathrm{C}$ for $24 \mathrm{~h}$, (d) $500^{\circ} \mathrm{C}$ for $48 \mathrm{~h}$ and (e) $500^{\circ} \mathrm{C}$ for $72 \mathrm{~h}$ (b-e: elastic-plastic-loaded)

(a)

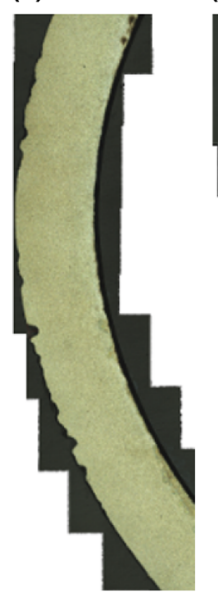

(b)

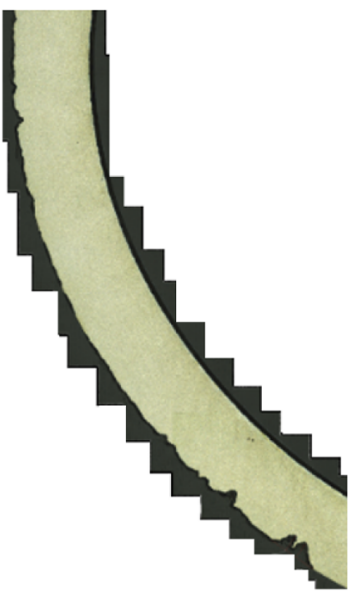

(c)

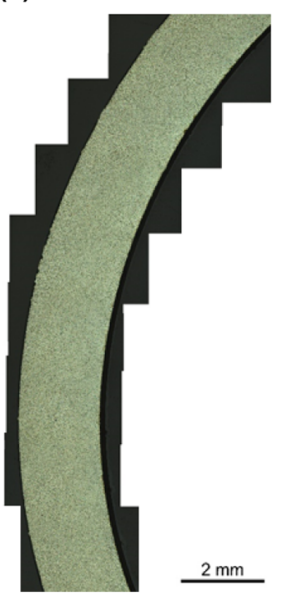

(d)

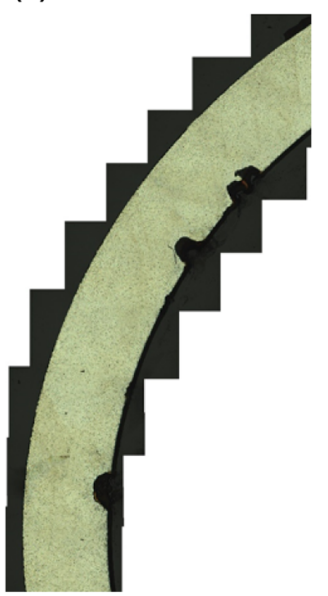

(e)

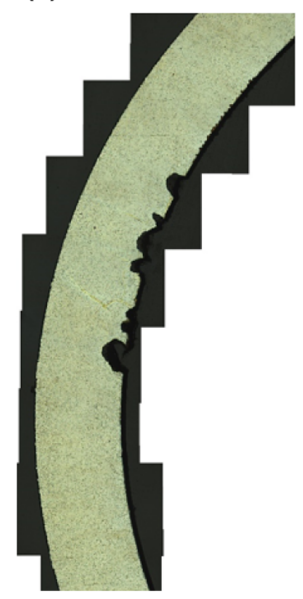

(f)

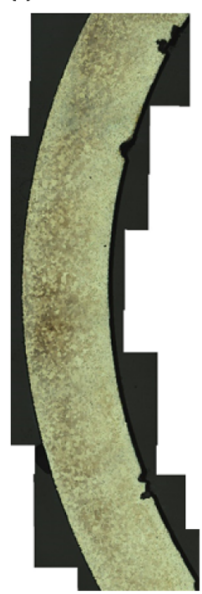

Fig. 6. Representative macrographs of C-rings after corrosion over 20 days: (a) as-extruded, only plastically deformed, (b) as-extruded, (c) $200^{\circ} \mathrm{C}$ for $4 \mathrm{~h}$, (d) $500^{\circ} \mathrm{C}$ for $24 \mathrm{~h},(\mathrm{e}) 500^{\circ} \mathrm{C}$ for $48 \mathrm{~h}$ and (f) $500^{\circ} \mathrm{C}$ for $72 \mathrm{~h}$ (b-f: elastic-plastic-loaded)

$200^{\circ} \mathrm{C}$ for $4 \mathrm{~h}$ (Fig. 6c) results in no significant pit formation on either the tensile side or the compression side. Only one large corrosion pit is found on the compression side. This heat treatment condition is the best among the investigated conditions. The grain size is still small, the amount of lamellar matrix LPSO structures is still adequate, and some residual stress from extrusion is relieved. In Fig. 6$\mathrm{d}-\mathrm{f}$, heat treatment at $500^{\circ} \mathrm{C}$ causes large corrosion pits after 20 days. Heat treatment at $500^{\circ} \mathrm{C}$ also causes elliptical pits and undercutting pits. Most of the pits are in the area opposite the C-ring opening, where the highest strain is expected. Furthermore, the as-extruded condition showed preferential corrosion on the tensile side and the $500^{\circ} \mathrm{C}$ heattreated samples corroded preferentially on the compression side. This result leads to the understanding that the fine-grained microstructure with matrix LPSO structures is not able to form a dense passive layer under tension stress when there is no stress relief heat treatment. Here, the aligned intermetallic phases seem to cause microgalvanic cells under sufficient residual stress, leading to a local porosity overlapped by tension stress and allowing a corrosion pit to grow. On the other hand, the coarse-grained structure with fewer matrix LPSO structures, fewer aligned intermetallics and more bulk LPSO phase is not resistant to pitting corrosion under compression stress. The bulk LPSO phases, which are greater distances apart than the intermetallics in the as-extruded condition, cause larger microgalvanic cells. The tensile and compressive strengths seem not to be related to the change in corrosion behavior: the as-extruded condition corrodes preferentially on the tension side and the heat-treated on the compression side. The yield strength asymmetry does not change significantly, and the compressive strength even increases in relation to the tensile strength. Using the elongation and compression at fracture also seems not to be related to the change in corrosion behavior: here, the values are higher under tension, being the highest in the as-extruded condition, precisely where the corrosion takes place.

The highest pitting resistivity to tensile and compressive stress is observed for the $200^{\circ} \mathrm{C}, 4 \mathrm{~h}$ 
treatment. The passive layer, built by the right interplay between grain size, reduced residual stress, matrix LPSO phase and aligned intermetallics, seems dense enough to avoid pitting.

Figure 7a-f shows micrographs of the largest corrosion pits in the C-rings after corrosion of plastically deformed Resoloy ${ }^{\mathbb{B}}$ in the as-extruded condition (Fig. 7a) and elastic-plastic-loaded in the as-extruded (Fig. 7b) and heat-treated conditions (Fig. 7c-f). The corrosion pit in Fig. 7c (heat treatment of $200^{\circ} \mathrm{C}$ for $4 \mathrm{~h}$ ) is the only pit found in this condition. None of the corrosion pits, neither elliptical nor wide shallow nor undercutting pits, show any crack initiation under constant loading. Therefore, none of the alloy conditions investigated show any hint of stress corrosion cracking on either the tensile side, which is more favorable to stress corrosion, or the compressive side. Figure $7 \mathrm{e}$ and $\mathrm{f}$ reveals a rather "edgy" corrosion morphology within the corrosion pits, which suggests an interaction with straight-lined microstructural features. Some of the large grains still contain lamellar matrix LPSO structures. However, there is a much smaller volume fraction of these structures after heat treatment at $500^{\circ} \mathrm{C}$, allowing the corrosion pit to form in the first place. It seems that the LPSO lamella act because of their higher composition of Dy and Nd and their well-ordered cathodic structure and remain until the anodic LPSO free matrix has corroded first.

Figure 8 shows cross-sectional SEM images of corrosion morphologies in the as-extruded Resoloy ${ }^{\circledR}$ after 7 days of immersion in the cell culture medium (Fig. 8a) and a heat-treated condition after $1 \mathrm{~h}$ immersion in simulated body fluid (Fig. 8b), based on previous research by Steinacker et al. ${ }^{33}$ The images support that the intermetallics (aligned in the vertical direction) are more noble and act as cathodes, causing the LPSO-free-Mg matrix to corrode first (see the change in color to darker gray and the cracks in Fig. 8a). Lamellar matrix LPSO structures with small distances between LPSO lamella slow corrosion, and the continuous network of stacking-ordered structures with a high density of $\mathrm{RE}$ and its passivating nature enable the formation of a protective surface layer (see Fig. $8 \mathrm{~b}$ ). When the distance between the LPSO lamella is slightly greater, the LPSO-free matrix corrodes first, and the LPSO lamella clearly act as cathodes.

Long distances between LPSO lamella and bulk LPSO phases, which cause microgalvanic cells to the LPSO-free matrix, can hinder the formation of a (a)

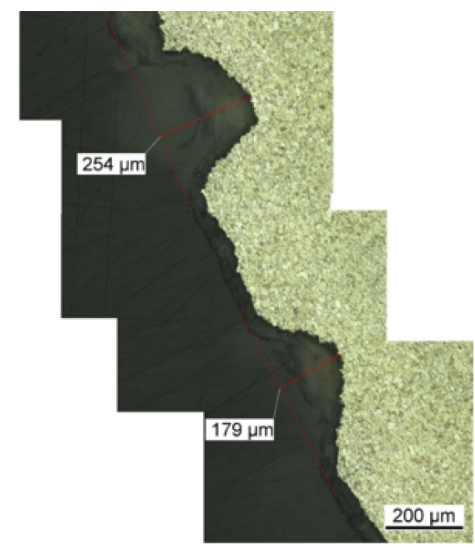

(d)

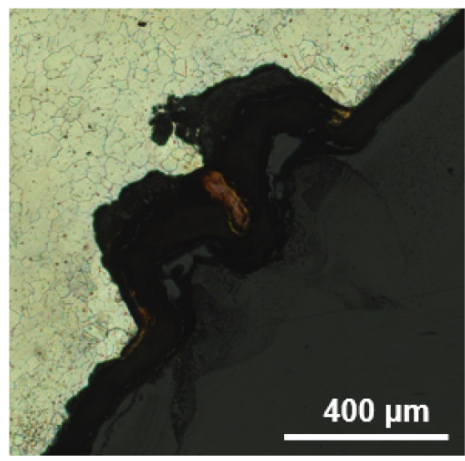

(b)

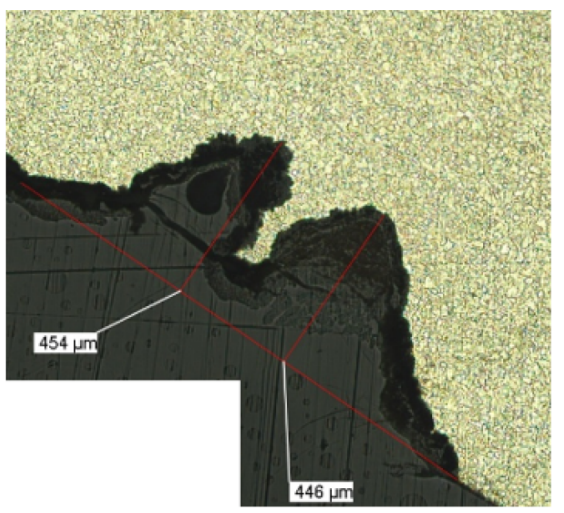

(e)

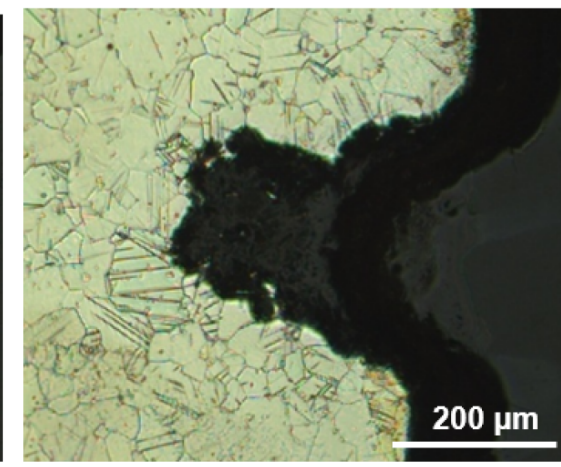

(c)

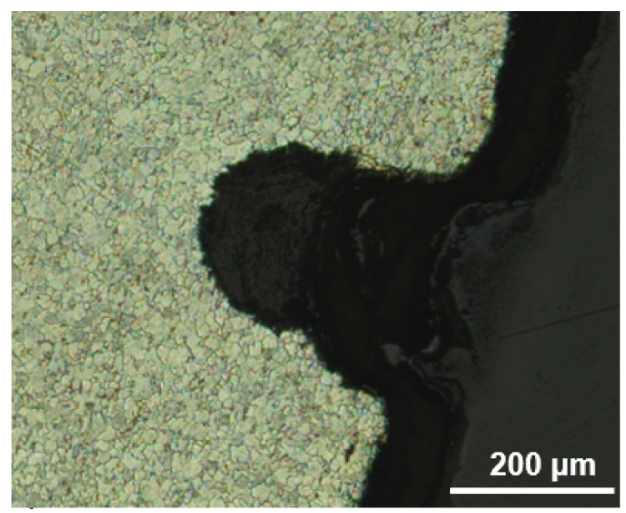

(f)

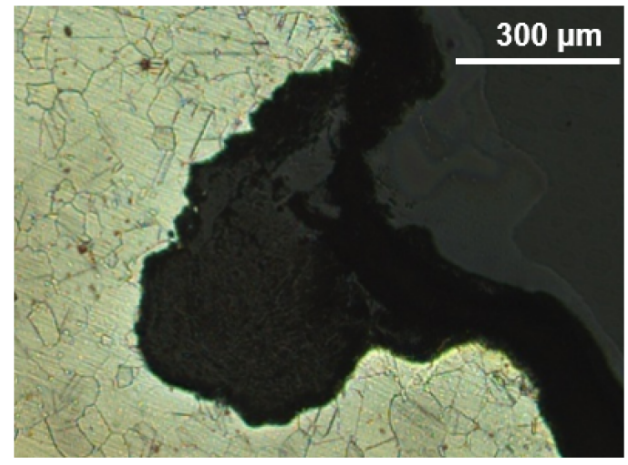

Fig. 7. Micrographs of pits in corroded C-Rings after corrosion over 20 days: (a) as-extruded, only plastically deformed, (b) as-extruded, elasticplastic-loaded, (c) $200^{\circ} \mathrm{C} 4 \mathrm{~h}$, (d) $500^{\circ} \mathrm{C} 24 \mathrm{~h}$, (e) $500^{\circ} \mathrm{C} 48 \mathrm{~h}$ and (f) $500^{\circ} \mathrm{C} 72 \mathrm{~h}$ showing worst case pitting corrosion 

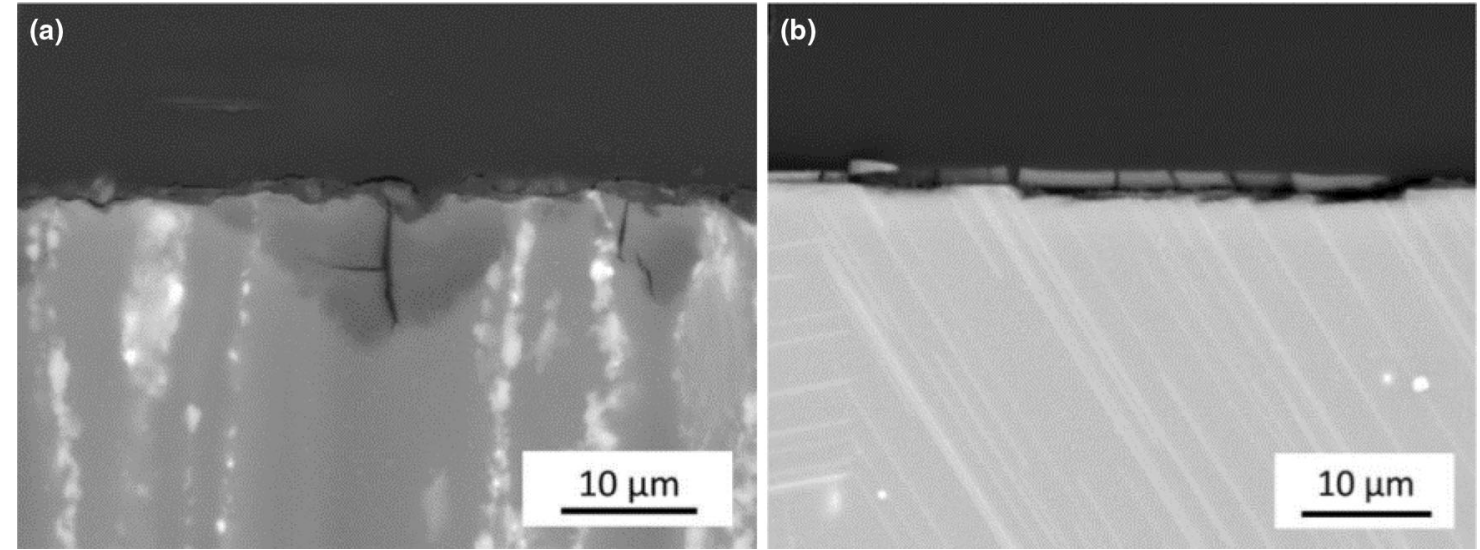

Fig. 8. SEM imaging of cross-sectional micrographs presenting corrosion morphology of (a) as-extruded Resoloy ${ }^{\circledR}$ after 7 days of immersion in cell culture medium and (b) a heat-treated condition after $1 \mathrm{~h}$ immersion in SBF

dense passive layer. These porous areas lead to channeling and initiate corrosion pitting. Therefore, a microstructure designed to resist pitting should have closely spaced LPSO lamellae, fine and recrystallized grains, and fine and uniformly dispersed intermetallics.

\section{CONCLUSION}

The comparison of the mechanical properties, microstructural features and corrosion behavior of Resoloy ${ }^{\circledR}$ in various heat-treated conditions to those of as-extruded conditions is the focus of this study. Tubes with an outer diameter of $35 \mathrm{~mm}$ and a wall thickness of $5 \mathrm{~mm}$ are hot-extruded after a short annealing after casting. The hardness and strength are found to be the highest in the as-extruded condition. The microstructure is homogeneously fine-grained recrystallized, and LPSO structures are found within the matrix grains. Annealing at $200^{\circ} \mathrm{C}$ for $4 \mathrm{~h}$ does not change the microstructure significantly but reduces the hardness as a result of relieving residual work hardening. Solution heat treatment at $500^{\circ} \mathrm{C}$ for $24 \mathrm{~h}$ and $48 \mathrm{~h}$ causes average grain growth, resulting in reduced hardness. The microstructure becomes inhomogeneous: medium grains have grown, and small bulk LPSO phases develop. While the matrix grain size increase after $72 \mathrm{~h}$ of annealing at $500^{\circ} \mathrm{C}$, additional formation of bulk LPSO phases leads to a slightly increased hardness. There is no obvious difference between the corrosion behaviors under different loading conditions for the as-extruded Resoloy ${ }^{\circledR}$ C-Rings over 20 days: both the "only plastically deformed" and "elastic-plastic-loaded" samples show a few corrosion pits on the tension side and no pits on the compression side. The short annealing at $200^{\circ} \mathrm{C}$ for $4 \mathrm{~h}$ improves the corrosion behavior on the tension side: no deep corrosion pits are found. However, annealing causes a stronger corrosion attack on the compression side. In particular, annealing at $500^{\circ} \mathrm{C}$ for $72 \mathrm{~h}$ causes grain growth and loss of LPSO structures in the matrix; large corrosion pits form, mostly elliptical shaped and wide and shallow, and some start to undercut. All the conditions survive the corrosion tests. Ultimately, Resoloy ${ }^{\circledR}$ is not free of pitting corrosion under the condition investigated, but none of the samples fails by cracking.

\section{ACKNOWLEDGEMENTS}

Open Access funding provided by Projekt DEAL. The authors acknowledge support from Hartmut Habeck for the corrosion measurements and Jens Wicke for the metallographic preparations.

\section{OPEN ACCESS}

This article is licensed under a Creative Commons Attribution 4.0 International License, which permits use, sharing, adaptation, distribution and reproduction in any medium or format, as long as you give appropriate credit to the original author(s) and the source, provide a link to the Creative Commons licence, and indicate if changes were made. The images or other third party material in this article are included in the article's Creative Commons licence, unless indicated otherwise in a credit line to the material. If material is not included in the article's Creative Commons licence and your intended use is not permitted by statutory regulation or exceeds the permitted use, you will need to obtain permission directly from the copyright holder. To view a copy of this licence, visit http://creativecommons.org/licenses/by/4.0/.

\section{ELECTRONIC SUPPLEMENTARY MATERIAL}

The online version of this article (https://doi.org/ 10.1007/s11837-020-04077-9) contains supplemen- 
tary material, which is available to authorized users.

\section{REFERENCES}

1. Y.F. Zheng, X.N. Gu, and F. Witte, Mater. Sci. Eng. $R$ 77, 1 (2014).

2. H.S. Brar, M.O. Platt, M. Sarntinoranont, P.I. Martin, and M.V. Manuel, JOM 61, 31 (2019).

3. M.P. Staiger, A.M. Pietak, J. Huadmai, and G. Dias, Biomaterials 27, 728 (2006).

4. A.G. Biotronik. www.biotronik.com/de-de/products/coronar $\mathrm{y} /$ magmaris.

5. C. Plaass, et al., J. Orthop. Sci. 23, 321 (2018).

6. L. Choudhary, R.K. Singh Raman, J. Hofstetter, and P.J. Uggowitzer, Mater. Sci. Eng. C 42, 629 (2014).

7. Y.H. Kang, Y.H. Kanga, D. Wu, R.S. Chen, E.H. Han, and J. Magnes, Alloys 2, 109 (2014).

8. P. Maier, N. Lauth, C.L. Mendis, M. Bechly, and N. Hort, JOM 71, 1426 (2019).

9. W. Jin, G. Wu, H. Feng, W. Wang, X. Zhang, and P.K. Chu, Corros. Sci. 94, 142 (2015).

10. T. Zhang, G. Meng, Y. Shao, Z. Cui, and F. Wang, Corros. Sci. 53, 2934 (2011).

11. R. Arrabal, A. Pardo, M.C. Merino, M. Mohedano, P. Casajús, K. Paucar, and G. Garcés, Corros. Sci. 55, 301 (2012).

12. Meko Laser Materials Processing. www.meko.de/Resoloy ${ }^{\circledR}$ : US patents: 9,566,367 B2 \& 9,522,219 B2, EU patents: $2744531 \& 2744532$

13. F. Feyerabend, J. Fischer, J. Holtz, F. Witte, R. Willumeit, H. Drücker, C. Vogt, and N. Hort, Acta Biomater. 6, 1834 (2010).

14. L. Yang, Y. Huang, Q. Peng, F. Feyerabend, K.U. Kainer, R. Willumeit, and N. Hort, Mater. Sci. Eng. B 176, 1827 (2011).

15. L. Yang, Y. Huang, F. Feyerabend, R. Willumeit, C.L. Mendis, K.U. Kainer, and N. Hort, Acta Biomater. 9, 8499 (2013).

16. S. Iwasawa, Y. Negishi, S. Kamado, Y. Kojima, and R. Ninomiya, J Jpn. Inst. Light Met. 44, 3 (1994).

17. D. Li, J. Dong, X. Zeng, C. Lu, and W. Ding, J. Alloys Compd. 439, 254 (2007).

18. D. Tolnai, P. Staron, A. Staeck, H. Eckerlebe, N. Schell, M. Müller, J. Gröbner, and N. Hort, Magnes. Technol., 17 (2016).

19. E. Koç, M.B. Kannan, M. Ünal, and E. Candan, J. Alloys Compd. 648, 291 (2015).

20. L. Yang, Development of Mg-RE alloys for medical application. Dissertation, Clausthal University of Technology, Germany (2013).

21. J.C. Gao, S. Wu, L. Qiao, and Y. Wang, Trans. Nonferrous Met. Soc. 18, 588 (2008)

22. Z.G. Huan, M.A. Leeflang, J. Zhou, L.E. Fratila-Apachitei, and J. Duszczyk, Mater. Sci. Mater. Med. 21, 2623 (2010).

23. P. Chen, L. Dong-Lin, Y. Jian-Xiong, T. Bi-Yu, P. Li-Ming, and D. Wen-Jiang, J. Alloys Compd. 485, 672 (2009).
24. M. Yamasaki, K. Hashimoto, K. Hagihara, and Y. Kawamura, Acta Mater. 59, 3646 (2011).

25. T.W. Fan, T. Bi-Yu, P. Li-Ming, and D. Wen-Jiang, Scr. Mater. 64, 942 (2011).

26. Y. Chen, Z. Xu, C. Smith, and J. Sankar, Acta Biomater. 10, 4561 (2014).

27. R. Lu, J. Wang, Y. Chen, D. Qin, W. Yang, and Z. Wu, J. Alloys Compd. 639, 541 (2015).

28. Q. Yang, B.L. Xiao, D. Wang, M.Y. Zheng, and Z.Y. Ma, Mater. Sci. Eng. A626, 275 (2015).

29. X. Zhang, Z. Ba, Z. Wang, and Y. Xue, Corros. Sci. 105, 68 (2015).

30. Z. Leng, J. Zhang, T. Yin, L. Zhang, X. Guo, Q. Peng, M. Zhang, and R. Wu, J. Mech. Behav. Biomed. Mater. 28, 332 (2013).

31. W. Liu, F. Cao, L. Chang, Z. Zhang, and J. Zhang, Corros. Sci. 51, 1334 (2009).

32. J. Liu, Y. Lin, D. Bian, M. Wang, Z. Lin, X. Chu, W. Li, Y. Liu, Z. Shen, Y. Liu, Y. Tong, Z. Xu, Y. Zhang, and Y. Zheng, Acta Biomater. 98, 50 (2019).

33. A. Steinacker, C.L. Mendis, M. Mohedano, F. Feyerabend, M. Stekker, P. Maier, K.U. Kainer, and N. Hort, Eur. Cells Mater. J. 32, 11 (2016).

34. ASTM - G46-94, Standard Guide for Examination and evaluation of Pitting Corrosion (2005).

35. P. Maier, J. Gonzalez, R. Peters, F. Feyerabend, T. Ebel, and N. Hort, Eur. Cells Mater. J. 32, 22 (2016).

36. Fort Wayne Metals. www.fwmetals.com/resoloy-a-magnesi um-alloy-for-absorbable-devices.

37. A.J. Griebel and J.E. Schaffer, Eur. Cells Mater. J. 32, 12 (2016).

38. X. An, S. Pixley, T. Hopkins, U. Adhikari, S. Khanal, N. Bhattarai, and K. Little, in Abstract Book of the 11th Symposium on Biodegradable Metals, InViv-5 (2019).

39. G.H. Koch, Tests for stress-corrosion. Adv. Mater. Process. 159, 36-38 (2001)

40. R.K. Singh Raman, Corrosion evaluation and monitoring practices. Industrial corrosion: evaluation and mitigation, 48 (2007)

41. N. Winzer, A. Atrens, G.L. Song, E. Ghali, W. Dietzel, K.U. Kainer, N. Hort, and C. Blawert, Adv. Eng. Mater. 7, 659 (2005).

42. S. Jafari, S.E. Harandi, and R.K. Singh Raman, JOM 67, 1143 (2015).

43. M.A. Timonova, Intercrystalline Corrosion and Corrosion of Metals under Stress, ed. I.A. Levin (London: Taylor \& Francis, 1962), p. 263.

44. L.L. Rokhlin, Magnesium Alloys Containing Rare Earth Metals (London: Taylor \& Francis, 2003).

45. F.R. Elsayed, N. Hort, M.A. Ordorica, and K.U. Kainer, Mater. Sci. Forum 690, 65 (2011).

Publisher's Note Springer Nature remains neutral with regard to jurisdictional claims in published maps and institutional affiliations. 